\title{
Festa Temática: da tradição à modernidade
}

\author{
Thematical Feast: from tradition to modernity
}

\section{Fiesta Temática: de la tradicion a la modernidad}

\begin{abstract}
Susana de Araujo Gastal ${ }^{1}$
Mariana Schwaab Machiavelli ${ }^{2}$

Liliane Stanisçuaski Guterres ${ }^{3}$
\end{abstract}

\begin{abstract}
Resumo
O festejar é uma forma de expressão pessoal e coletiva, presente em diferentes culturas, o que transforma a festa em um acontecimento importante para indivíduos e comunidades. No sul do Brasil as festas, ditas populares e com aspiração a serem vistas como tradicionais, são comuns e, hoje, não raro criticadas pelo que seria sua falta de autenticidade em relação às culturas locais que as originam. O presente artigo discute essa questão, buscando reconstruir o percurso histórico das festas, na Modernidade, a partir da presença das grandes exposições mundiais europeias da segunda metade do século XIX. Transpostas para o Brasil, tais eventos irão influenciar a organização das festas locais, inclusive as populares, buscando adaptá-las às novas demandas por lazer e entretenimento. Outra vertente a influenciar tais festas, na segunda metade do século XX, será o Carnaval, tanto em termos estéticos como pela expansão de seu know how para além da estrutura das escolas de samba. Face às novas especificidades, propõe-se denominar como festa temática, os eventos concebidos dentro dessa nova lógica.
\end{abstract}

Palavras-chave: Turismo. Festa Temática. Modernidade. Rio Grande do Sul/Brasil.

\begin{abstract}
To celebrate is a personal and collective form of expression, present in different cultures, making the feast a major event for individuals and communities. Nowadays the popular feasts are very common in southern Brazil, but often criticized for its lack of authenticity in its

\footnotetext{
${ }^{1}$ Doutora em Comunicação Social. Professora, pesquisadora e orientadora da graduação e do programa de PósGraduação em Turismo -Mestrado da Universidade de Caxias do Sul-RS. Brasil. sgastal@ terra.com.br

${ }^{2}$ Mestranda do Programa de Pós-Graduação em Turismo -Mestrado, da Universidade de Caxias do Sul-RS. Brasil.

${ }^{3}$ Doutora em . Professora, pesquisadora e orientadora do programa de Pós-Graduação em Turismo -Mestrado da Universidade de Caxias do Sul-RS. Brasil. lsguterr@ucs.br
} 
relation to local cultures. This article proposes to reconstruct the historical background of the feasts in modernity from the great world exhibitions of European second half of the nineteenth century to carnival aesthetic influence in the second half of the twentieth century. These events influenced the organization of local feast in Brazil, including the popular one, trying to adapt them to new modern demands for leisure and entertainment. This article is mostly based on it to propose the term "thematical feast" to design these events in this new logic.

Keywords: Tourism. Thematical Feast. Modernity. Rio Grande do Sul/Brasil.

\section{Resumen}

El festejar es una forma de expresión personal y colectiva, presente en diferentes culturas, las cuales transforman la fiesta en un gran evento para los individuos y las comunidades. En el sur de Brasil, las fiestas son comunes y vistas como populares y con aspiración a tradicionales, lo que a menudo es criticado por lo que sería su falta de autenticidad en relación con las culturas locales que las originan. En el artículo se discute el tema, buscando reconstruir el histórico de las fiestas a partir de la Modernidad e de la presencia de las exposiciones universales europeas del siglo XIX. Implementado en Brasil, estos eventos influyen en la organización de los festivales locales, incluido los populares, que tratan de adaptarse a las nuevas demandas de ocio y entretenimiento. Otro aspecto que influye en estas fiestas, en la segunda mitad del siglo XX, es el carnaval. La influencia será tanto estética como de la aplicación de los conocimientos de las escuelas de samba. Dadas las nuevas características, se propone que se llame como fiestas temáticas a los acontecimientos organizados en esta nueva lógica.

Palabras clave: Turismo. Fiesta Temática. Modernidad. Rio Grande do Sul / Brasil.

\section{Introdução}

Presente desde os momentos mais remotos da civilização, o festejar seria inerente à condição humana, sendo a festa, sua decorrência. A festa estaria associada, primeiro, aos ritos de saudação à divindade, assim como aos momentos da colheita ou mesmo às cerimônias fúnebres. O mundo da religiosidade judaico-cristã separa o sagrado do profano, ficando a festa na esfera do segundo. Nessa condição, ela irá dominar diferentes dimensões de vida, marcando nascimentos, casamentos e outros ritos de passagem. Permeará a sociedade como um todo, independente de classe social ou de condição econômica. Em decorrência disso, irá envolver não apenas seus promotores - famílias, clãs, empresas, comunidades... - mas significará momentos de estar com o outro, de receber o outro como parente, amigo, conviva 
e, em tempos mais recentes, incluir nesta condição o visitante e o turista. Isso não significa dizer que a festa, na sua organização e desfrute, esteja isenta de conflito, mesmo que a literatura especializada tenda a valorizá-la nos seus aspectos de gozo, enaltecimento, harmonia e união.

No século XIX, a Modernidade, em especial na sua associação à expansão capitalista e ao sistema de fábricas (PESAVENTO, 1997), irá reduzir a festa à dimensão do lazer e este, à do consumo, construindo-se, por esse viés, a sua aproximação ao turismo. O turismo teve sua consolidação em concomitância à Revolução Industrial, beneficiando-se dos novos processos e técnicas de comunicação e transporte que então iam sendo implementados. Fruto do mesmo momento, e atendendo às demandas dos novos processos industriais que então se impunham e precisavam mostrar os produtos fabricados aos diferentes públicos, surgem na Europa as exposições mundiais, como "elementos de difusão/aceitação das imagens, ideais e crenças pertinentes ao ethos burguês" (PASAVENTO 1997, p. 15).

O que se pretende destacar, no corpo do presente artigo, é que as práticas das exposições-feira induzem um novo pensar sobre a festa, no qual se associa a ideia de gozo e alegria, ao desfrute de um evento planejado e, mesmo quando não se coloque propriamente como um produto de mercado, com lógicas associadas a outras questões que não apenas o extravasamento social e individual, e a expressão da cultura local. Ou melhor, estaríamos em presença da consolidação de novos hábitos e comportamentos, nos quais a expressão cultural não mais se coloca como decorrência da forte presença do território, como nas culturas tradicionais, mas ante as novas identificações, associadas à Modernidade, agora permeadas pela máquina e pela produção em massa de objetos. O cenário preferencial dessas novas práticas será a cidade, embora, como aponta Ribeiro (1998) ao analisar as festas no Sul do Brasil, o calendário festivo local demonstre, não raro, estreita relação entre o meio urbano e o rural. Tal associação se daria nas definições das principais festas locais, principalmente em municípios de economia agrícola, mesmo quando estas aconteçam na cidade.

A aproximação aqui pretendida filia-se ao proposto por Trigo (2003, p.26), quando coloca o entretenimento como "atividade programada e geralmente paga", em oposição aos discursos de viés sociológico e antropológico sobre o lazer, centrados na ênfase no sujeito e na cultura local. Considera-se a migração para o espaço urbano de festejos antes associados aos círculos 
de produção agrícola, na forma de festas, e as especificidades associadas ao novo espaço. Busca-se, como hipótese, que este padrão seria alimentado a partir do modelo das feiras mundiais, iniciadas em Londres, em 1851, e que na sua versão mais contemporânea, conforme praticadas largamente no Rio Grande do Sul, as mesmas se beneficiariam, ainda, das tecnologias e da estética de diálogo com a dimensão urbana, desenvolvidos pelo carnaval, uma manifestação popular de "natureza espetacular" (CAVALCANTI, 2002, p.37), que nasce e se expande na cidade, onde instaura 'um espaço-tempo urbano próprio à realização da festa [...]" (FERREIRA, 2009, p.25).

As evidências aqui apresentadas para discussão alimentam-se de dados empíricos colhidos no âmbito de uma pesquisa mais ampla, que objetiva traçar a construção do campo do Turismo no sul do Brasil, mais especificamente no Estado do Rio Grande do Sul, ao longo do século XX. Tal investigação detectou que, em 2011, o Calendário de Eventos da Secretaria Estadual de Turismo registrou vinte "festas", conforme a Tabela 1, apresentada adiante, que tinham no seu título ênfase em produtos e expressões da economia e da cultura locais. Analisou-se com mais vagar estudos sobre as festas da Uva, do Peixe, Festqueijo, do Champanha, do Pinhão, da Colônia, das Tradições Gaúchas, das Tradições Italianas e Natal Luz ${ }^{4}$. Sem pretensão a uma generalização mais ampla, o intuito é o de reunir algumas evidências, como o número de festas realizadas no Estado, e a partir delas destacar as especificidades que, a priori, se destacam pela presença recorrente desse tipo de evento, na região. A análise do material empírico enfatiza que, a par sua proposta cultural associada às identidades e tradições locais, há outras questões repetitivamente presentes, que permitem que se encaminhe a proposta da utilização da expressão festa temática para as qualificar e conceituar.

A discussão a seguir se dá em três momentos. O primeiro contextualiza a festa em termos teóricos, com especial ênfase na passagem do festejar das culturas tradicionais ao padrão de festejar introduzido pela Modernidade. O segundo momento traça o percurso histórico das festas realizadas no Brasil - e mais especificamente no Rio Grande do Sul - a partir da matriz das exposições mundiais e do carnaval das Escolas de Samba. No terceiro momento, por fim,

\footnotetext{
${ }^{4}$ Disponíveis em http://www.ucs.br/ucs/posgraduacao/strictosensu/turismo/dissertacoes/apresentacao, acesso em 20 abril de 2011.
} 
reúnem-se evidências que buscam sustentar a proposição do conceito festa temática, para qualificar os eventos realizados amplamente no sul do Brasil.

\section{A Festa}

A festa, na contemporaneidade, implicaria em uma intervenção organizativa no que seria, antes, uma manifestação humana espontânea. Tal gama de manifestações, indo da espontaneidade à organização, leva à polêmica quando estudos teóricos buscam uma melhor compreensão desse fenômeno social, independente da disciplina em que seja estudado (AMARAL, 2008). Esta antropóloga questiona o ver, entre os pressupostos da festa, apenas o divertimento e o momento de escape à monotonia do cotidiano e ao trabalho pela sobrevivência, muitas vezes colocados como aquela fuga que tornaria possível a vida em comunidade. Para Amaral, analisar a festa como uma válvula de escape é deixar de compreender o caráter de ação transformadora que ela encerra, a mediação que faz entre utopia e ação/realização. Para Bakhtin (2002), a origem das festas não precisa e nem deve ter uma possível explicação a apresentá-la como produto das condições e finalidades práticas do trabalho coletivo ou de uma necessidade biológica, pois elas exprimiriam, antes de tudo, uma visão de mundo:

[...] a Festa é isenta de todo sentido utilitário (é um repouso, uma trégua, etc.). É a Festa que, libertando de todo utilitarismo, de toda finalidade prática, fornece o meio de entrar temporariamente no universo utópico. É preciso não reduzir a Festa a um conteúdo determinado e limitado (por exemplo, à celebração de um acontecimento histórico), pois na realidade ela transgride automaticamente esses limites. É preciso também não arrancar a Festa à vida do corpo, da terra, da natureza, do cosmos (BAKHTIN, 2002, p.241).

Assim, explica o teórico, a origem da Festa estaria no mundo das ideias e dos ideais, nascendo não da obrigatoriedade de proporcionar descanso ao corpo, mas sim "dos fins superiores da existência humana" (BAKHTIN, 2002, p.7). Nessa concepção, portanto, "a atividade festiva não se reduz a nenhum artificialismo, qualquer que seja. Seu sentido supera sempre uma instituição voluntária" (AMARAL, 2008, p.80), o tema da festa sendo então e por definição, o 
festejar em si mesmo. Nesses termos, falar em festa associa-se ao falar de cultura, pois o momento e contexto de sua realização se configurariam como expressão simbólica no e para o grupo social envolvido. Ato contínuo, as festas teriam importância fundamental para a compreensão da estruturação da sociedade, pois expressariam, ainda, o inconsciente coletivo.

Macedo (1986, p.184) chama a atenção que a festa "cimenta o sentimento coletivo", ou seja: "as festas são uma dimensão da vida. Contribuem para promover o sentimento especial de estar junto e configuram o espaço social privilegiado do acontecimento extraordinário [...] são uma expressão e afirmação de valores. Está presente nelas o esforço de construção de uma imagem que é a representação da visão ideal do grupo".

Ribeiro (2002), que estudou a Festa da Uva de Caxias do Sul - uma festa realizada no Rio Grande do Sul, desde 1931 -, afirma que se festeja para mostrar o que somos e o que fazemos até porque somos o que fazemos. Ressalta que as transformações e mudanças que nós operamos no modo de fazê-las e na forma de organizá-las, seria o que nós somos. A autora defende que a promoção das festas traz inúmeros benefícios à comunidade local e aos turistas, filiando-se aos que a colocam como uma relação marcada pelo tempo festivo ou tempo cerimonial, em oposição ao tempo de trabalho. Esse seria um tempo de ruptura, que apresentaria uma diferença de conteúdo em relação ao tempo de trabalho. Ribeiro sustenta que reconhecer o tempo festivo como outro tempo é perceber uma diferença de atitude: o trabalho seria um tempo e uma atividade sérios, enquanto a festa seria um tempo e uma atividade, alegres.

As festas mantêm com o cotidiano uma relação de licença poética: sem dele se esquecerem, até porque supõem laboriosos preparativos e meticulosa organização, dele se afastam temporariamente, introduzindo-nos num tempo especial por meio de elaborada linguagem artística e simbólica. Um tempo cíclico, fortemente ligado à experiência vital, cheio de conteúdos cognitivos e afetivos. Um tempo que entrecruza o calendário histórico e traz de volta, a cada ano, as diferentes festas do calendário popular (CAVALCANTI, 1998, p. 294).

Quando a festa se coloca como evento, reforça-se seu desempenho como esforços e ações planejadas com o objetivo de alcançar resultados, ou seja, ela será estrutural e comercialmente organizada como produto de mercado. Nesses termos, a ênfase desloca-se do sociológico para 
o campo da organização e da gestão, mesmo que elas não sejam "simplesmente 'eventos', mas sim a culminância de processos culturais que, não raramente, se estendem ao longo do ano. Das mais tradicionais às mais modernas, deitam raízes profundas na vida dos grupos que as promovem" (CAVALCANTI, 1998, p.297). Caso sejam vistas apenas sob o ponto de vista do evento, seriam

[...] um produto e, partindo da premissa de que é uma atividade destinada a gerar lucros, direta ou indiretamente, a todos os envolvidos, é fácil depreender que se trata de um produto de extremo valor e deve ser explorado e oferecido a um público ávido de informação, conhecimento, inovações tecnológicas, lançamentos para a sua área de atuação, entretenimentos, e tudo aquilo que pode ser representado como novas experiências e emoções (ZOTTIS, 2003, p. 4).

Significa dizer que a festa, assim posto, implicaria uma intervenção organizativa no que seria uma manifestação humana universal. As transformações na dinâmica social interferem na dinâmica das festas, como no caso da Modernidade, que impõe a lógica da produção e do consumo ao campo do entretenimento. Villadary (1968, p.12), por sua vez, recusa a oposição ordem e espontaneidade para compreender as festas, pois, segundo ele "a festa provém da mais regulamentada das instituições e da espontaneidade a mais inesperada. Enquanto fenômeno social ela possui regras, leis, uma lógica própria que é passível de se encontrar na maior parte das cerimônias em numerosas sociedades no curso da história". Em sua análise, as festas apresentam traços que as caracterizam, criando um estilo no qual a emoção e a afetividade afloram através do alto poder de coesão que elas determinam, podendo "se diluir e se transformar em lazer e em espetáculo" (Idem).

Do ponto de vista do Turismo, as festas tornaram-se importantes como atrativos que induzem a mobilização de turistas e visitantes, além de poder contribuir para qualificação da imagem das localidades que as realizam. O exemplo do Rio de Janeiro é significativo nesses termos, pois já em 1932, a oficialização da festa local de carnaval se dá no corpo de um planejamento que tinha como objetivo projetar a cidade como centro turístico, numa linha de tempo que teve, antes, a inauguração do hotel Copacabana Palace (1923) e a fundação da Sociedade Brasileira de Turismo, depois Touring Club do Brasil (1926), que se associaria à Prefeitura 
local para a organização do carnaval (GUIMARÃES, 2009). Nesses termos, as festas podem ser um item num produto turístico mais amplo, ou se colocar como o produto turístico em si, e nessa condição, não raro, ser o principal atrativo de algumas cidades. Como atrativo principal da localidade, são em muitos casos organizadas e promovidas de forma amadora, em modelos de gestão centrados em comissões comunitárias e dependendo do trabalho voluntário dos cidadãos (ZOTTIS, 2003).

Ribeiro (2004) aponta para o fato de que, no Sul do Brasil, o calendário festivo demonstra a estreita relação entre o meio rural e o urbano nas definições das suas principais festas, em especial em municípios de economia agrícola. Analisando as festas religiosas, o pesquisador salienta que elas estão "centradas nos devotos e nos grupos de atores sociais que permeiam o universo sacro e ao mesmo tempo profano de tais manifestações" (RIBEIRO, 2004, p. 48), mas alerta que "as manifestações culturais correm o risco de sofrer mudanças quando tratadas de forma massiva, repetitivas e acatando o gosto do visitante, neste caso operadores turísticos e turistas" (Idem). Aceitar ou não tais mudanças faria parte de um processo de negociação para avaliar "quais interesses estão em jogo para permitir e facilitar que se mudem desde as datas festivas aos rituais dessas manifestações a partir de atores sociais envolvidos no processo" (Idem).

As festas populares, ainda segundo Ribeiro (2004), podem ser divididas em religiosas, se acompanhadas de rituais da igreja; profano-religiosas, se feitas por leigos, mas com aceite de religiosos; profanas, como aquelas com caráter de diversão e com o propósito de "segurar os visitantes o maior tempo possível nas festas com leilões, danças, comidas, barraquinhas e folguedos como malhação de Judas" (p.50). O autor ainda considera que a festa produto turístico seria aquela apta a atrair não apenas devotos, mas visitantes movidos por afinidade, curiosidade, busca por novas experiências ou por evasão dos cotidianos. Ribeiro afirma que mudanças redimensionam espaços e serviços e que, uma vez redimensionada, a festa passa a compor um produto cultural turístico, "sendo uma das consequências a perda de autenticidade" (idem, p.48). Cita Alcalde e González (1989, p.114) para distinguir quatro dimensões das festas e fenômenos festivos: Sociopolítico; Econômico; Estético; e Simbólico, sendo este o mais importante porque estaria "presente em todo fenômeno festivo, definindo e 
reproduzindo simbolicamente a identidade de uma coletividade ou grupo social" (RIBEIRO, 2004, p.48).

Noutra linha está a discussão proposta por Nery (2011), quando analisa o Centro Luiz Gonzaga de Tradições Nordestinas e as festas-feira ali realizadas, marcadas por "música alta [que] ultrapassava as barreiras físicas" (p.35) e por "cheiros variados [que] nos recebiam" (idem, p.35). Considerando o proposto por Ribeiro e o enfoque de Nery, se estaria em presença de fenômenos diferenciados entre si, levando a que, hoje, mesmo festas como "o Boi Bumbá de Parintins ou o carnaval carioca desafiam tipificações e análises estanques, integrando no seu desenvolvimento aspectos muito tradicionais, comunitários, e mesmo personalistas, a dimensões hiper-modernas, massivas, mercadológicas e espetaculares" (CAVALCANTI, 1998, p.303).

Teríamos, então, de um lado, as festas ditas populares, com dificuldades de se manterem como tal, justo por precisarem conviver não só com o turismo, mas também com um imaginário que, como será proposto, difunde-se a partir da Modernidade e das feiras universais, levando a que sejam tratadas como eventos. Por outro, o mesmo popular revisitado a partir da presença da nova lógica, filha da Modernidade, como abordado no próximo item, criaria os quadros descritos por Nery. O percurso histórico a ser descrito a seguir, inclui apenas as festas profanas, para nelas pontuar os desdobramentos no Brasil e no Rio Grande do Sul, da influência das feiras universais e, nas décadas finais do século XX, da tecnologia e da visualidade do carnaval, mesmo que essas festas aconteçam em íntima relação com as comunidades locais.

\section{A Festa e seu Percurso Histórico}

Nas culturas tradicionais, o agrícola e o religioso destacam-se como motivações ao festejar. A construção de igrejas traz o culto à divindade para dentro da cidade e, com ele, a festa também se urbaniza. Uma das primeiras festas a surgir como fruto da cidade e suas lógicas será o carnaval, cujos registros mais antigos estariam em Nice, em 1294 (FERREIRA, 2009). A Modernidade, em especial após a Revolução Industrial do século XIX, acelera o processo de 
urbanização da atividade econômica, altera modelos de vida e, em decorrência, as maneiras de festejar.

Talvez se pudesse afirmar, inclusive, que uma das mudanças importantes nessa passagem da lógica tradicional para lógica moderna, é que junto com as transformações do lazer em produto de mercado, o imaginário festa, alimentado pela ênfase na alegria, no gozo e no excitamento decorrente do estar juntos, sejam agregados a produtos como as viagens, as feiras comerciais e industriais, os parques de diversão e outras manifestações da agora denominada indústria cultural. O novo sistema reproduz em quantidade livros, discos e filmes que, além da expressão 'cultural' agregada, tem como marcas o entreter e o se colocar como acontecimento marcado pela intensidade e pela espetacularização. Retomando o exemplo de Nice, o século XIX encontrará a cidade com uma "identidade francesa e internacional, não só por meio do olhar externo (Nice como paraíso do lazer), mas a partir de sua herança cultural: sua urbanização, suas festas e seus costumes populares" (FERREIRA, 2009, p. 19, grifo nosso), sempre destacados como importantes por trazer nova fonte de recursos para a cidade e seus habitantes.

As lógicas de entretenimento e acontecimento intenso e espetacular seriam as marcas diferenciais, por exemplo, das exposições mundiais. Já na primeira, realizada em Londres, em 1851, com a denominação de Great Exhibition of the Works of Industry of All Nations ${ }^{5}$, o objetivo era o de criar um grande palco para exibir os novos materiais e os novos produtos industriais, ora lançados no mercado, assim como demonstrar suas possibilidades de utilização. Daí Pesavento (1997, p. 14) falar nessas feiras como "arma de demonstração", por estarem, segundo a historiadora, a serviço da circulação de mercadoria em escala internacional, mas também de imagens, ideias e crenças pertinentes ao ideário burguês, nesse novo processo econômico. A exposição de Londres consagrou o Palácio de Cristal e tinha como atrações jardins, fontes luminosas, restaurantes e festas noturnas, cuja marca seria a de serem espetaculares. Ainda segundo Trigo (2003, p. 52): “Cada área possuía um tema específico: história do trabalho, história da habitação humana, técnicas de higiene, exposições

\footnotetext{
${ }^{5}$ Esta não seria primeira exposição dedicada à indústria, pois a França já realizara tais mostras desde o final do século XVIII. A inglesa será a primeira a, na sua dimensão, incluir a representação de diferentes países (PESAVENTO, 1997) e atrair, em decorrência, visitantes de todo mundo.
} 
coloniais, etc. Daí vem a expressão 'exposição temática' (que originou os parques temáticos)", reportando aos espaços da feira.

Em 1889, Paris realizou a sua Exposição Universal, que teve entre seus atrativos a Torre Eiffel, cujo objetivo era o de mostrar as possibilidades para a utilização do ferro. O papel da Torre Eiffel na exposição, seria, talvez, o ideal para exemplificar o já colocado sobre a importância das exposições da segunda metade do século XIX, em termos de serem utilizadas "pela burguesia industrial como instrumento de propaganda e como palco para ampliar seus negócios [...]" (MACHADO, 1990, p. 73), num mundo que se industrializava e precisava de mercado para seus produtos.

O entretenimento, na lógica das feiras mundiais, então, passaria a estar associado não só ao lazer, mas também ao caráter educativo das mesmas - as pessoas precisariam aprender a utilizar os novos produtos industriais -, de maneira que a "educação proposta às massas deveria ser feita de forma leve e sedutora" (TRIGO, 2003, p. 52). A lógica do entretenimento, que se imporia, tinha como objetivo "menos de instruir os cientistas, do que de maravilhar os leigos; o visitante [...] busca, sobretudo, distrair-se [...]" (TRIGO, 2003, p.52), e nesses termos deverá ser atendido.

No Brasil, dentro dessa lógica e tentando transpor os modelos europeus, a primeira exposição ocorreu em 1861 e foi montada na Escola Central, no Rio de Janeiro, em prédio cedido pelo Ministério da Guerra. Em 1900, será a vez da Exposição Artístico-Industrial Fluminense, cujo relatório, de 1901, registrava que "nenhum paiz [sic] onde impere a civilização e haja aspiração ao engrandecimento poderá ser indiferente aos resultados que se tem colhido das exposições [...]" (apud MACHADO, 1990, p.83). Esta exposição teve por mote comemorar o quarto centenário do descobrimento do Brasil. Mucio Teixeira, membro da diretoria da Sociedade Propagadora das Belas Artes, promotora do evento fluminense, registrava que "as exposições são syntheses da actividade dos povos. Ellas representam o duplo papel do esforço individual, na esphera especulativa e da consagração moral do trabalho, que é o principal agente da paz e do progresso" (apud MACHADO, 1990, p.85).

Tais afirmações ilustram o que Pesavento (1997, p. 16) coloca como o que seria o assumir a condição burguesa, pelas elites locais latino-americanas, "ao passo que paulatinamente se 
transformam as condições de produção. É esta circularidade de práticas e ideias que permite que o discurso da burguesia europeia seja entendido e 'vertido' ou 'metabolizado' pelos representantes da elite progressista de extração colonial", as exposições colocando-se como cenário ideal para tal.

Retomando o Brasil, ainda em 1908 houve a Exposição Nacional comemorativa ao Centenário da Abertura dos Portos, a primeira a extrapolar o âmbito de um único prédio, e ter a participação dos Estados com pavilhões próprios. O Rio Grande do Sul esteve entre os participantes, presença essa que, segundo o jornal A Federação, em 13 de agosto de 1908, "produziu grande entusiasmo [por] suas indústrias, quantidade de variedade de produtos, erguendo-o a vanguarda nacional" (apud MACHADO, 1990, p.91). Em 1922, será a vez de comemorar outra efeméride, com a Exposição Internacional do Centenário da Independência, realizada no Rio de Janeiro, que além da representação dos Estados, contou com representações estrangeiras. Tais eventos propagaram-se pelo país, apresentando uma nova maneira de festejar, comemorar e estar juntos - pois, deveriam ser modernos -, mas também impondo a ideologia burguesa industrial. A proposta de colocar-se como atrativo universal, ou seja, para além do perímetro local de sua realização física, torna a sua associação ao turismo como decorrência 'lógica' e 'natural'.

Nestes termos, o Rio Grande do Sul, a seguir analisado, coloca-se apenas como recorte, para maior compreensão desse novo perfil de festas, pois o Estado sulino também se marcará pela realização de exposições. Em 1875 foi realizada em Porto Alegre a Exposição Comercial e Industrial, no edifício do Ateneu Rio-Grandense. Nela, há uma ampla sessão de artes e fotografias. Outra grande exposição é realizada em 1881, a Exposição Brasileiro-Alemã.

Em suas seções e estandes exibem-se os mais variados produtos procedentes de todas as regiões da Província - o couro, a lã, o linho, os cereais, as essências nativas, os cristais de rocha, os mármores, o carvão - a que se associam, os bem sucedidos esforços de uma indústria nascente mas já bem definida em seus propósitos e cujos êxitos se tornam evidentes na apreciável qualidade de diversos artigos - tecidos, calçados, chapéus, peças de correaria, mobiliário, vinhos, embutidos, drogas farmacêuticas, conservas de várias espécies, etc. Paralelamente a esse desabrochar de energias, a esse concerto de forças que se disciplina na órbita das atividades práticas, acentuam-se os traços, por vezes singulares, da fisionomia moral e intelectual da Província (DAMASCENO, 1971, p. 113-114). 
Em 1901 foi realizada, em Porto Alegre, a Grande Exposição Estadual; entre seus pavilhões, um foi destinado para "concertos, restaurantes, fontes luminosas, jardins viveiros de aves, grutas decorativa, etc." (MACEDO, 1873 apud MACHADO, 1990, p.89). "A partir da década de 1930, foram comuns as exposições agrícolas, rurais, avícolas, pecuárias e industriais em diversas cidades do Rio Grande do Sul. Em 1931, ocorrera a Exposição Estadual Rural" (POSSAMAI, 2007, p.2). Apenas em 1934, foram realizadas no Estado, a $1^{\circ}$ Exposição Agrícola, Industrial e Pastoril de Santa Rosa; a $2^{\circ}$ Exposição Agro-Pecuária e Industrial de São Borja; a Exposição Agrícola, Industrial e Pastoril de Carazinho; a Exposição AgroPecuária de Vacaria; a Exposição Agro-Pecuária de Bagé; a Exposição de Bebidas em Montenegro; a Exposição Comemorativa da Imigração Alemã em São Leopoldo. Esses eventos acontecem no espaço urbano, ou muito próximo a ele, embora a temática, como suas denominações indicam, na sua maioria seja rural. A maior aproximação das festas com o turismo, entretanto, acontece com a realização da primeira Festa da Uva em Caxias do Sul, em 1931, e da Exposição Centenário Farroupilha, montada em Porto Alegre, em 1935.

A primeira Festa da Uva originou-se em torno de uma exposição da fruta, realizada num clube local. O sucesso da primeira edição motivou a realização de uma nova festa no ano seguinte, desta vez na praça central de Caxias do Sul, que contou com um desfile de alegorias sobre rodas, puxadas por juntas de bois e cavalos, representando a produção rural da região. Já em 1933 foram agregadas atividades que depois se tornaram tradição, como a escolha da rainha e o desfile de carros alegóricos, então conhecido como "parada da uva". A sexta edição, comemorativa aos 75 anos da colonização italiana no Rio Grande do Sul, foi a primeira a ter a presença de um presidente da República, na ocasião, Eurico Gaspar Dutra. Ao longo de 28 edições até 2012, a Feira Agroindustrial, realizada como parte dos festejos, expandiu-se, em detrimento da presença de manifestações da cultura popular local. ${ }^{6}$

A Exposição do Centenário Farroupilha, a exemplo das exposições mundiais internacionais, teve como objetivo apresentar os avanços do Estado, mostrando que "o Rio Grande do Sul de hoje, na esfera fecunda de seu trabalho construtivo, é bem digno do Rio Grande de hontem

\footnotetext{
${ }^{6}$ Disponível em <http://www.festanacionaldauva.com.br>, acessado em 10 de maio de 2011.
} 
[sic], na ação épica dos seus heróis”, como ficou registrado no seu Regulamento Geral ${ }^{7}$. A exposição, mais propriamente, incluiu o Pavilhão da Agricultura (804 expositores), o Pavilhão Industrial (905 expositores), o Pavilhão das Industriais Estrangeiras, envolvendo 137 expositores, e o Pavilhão Cultural. Vários estados brasileiros participaram com pavilhões próprios. Outras atrações foram o Cassino, que promovia bailes e outras festas aristocráticas, e uma churrascaria, que teria sido a primeira do Estado. Com objetivos explícitos de que Porto Alegre se tornasse "a Meca dos forasteiros de toda parte do Continente", conforme o jornal Correio do Povo (apud MACHADO, 1990, p. 114), ao seu final recebera mais de um milhão de visitantes, muitos vindos em caravanas do interior do Estado. Esses visitantes eram recebidos no Pórtico Monumental, que abria a exposição, onde funcionou a central de atendimento aos visitantes. A Exposição do Centenário Farroupilha foi um marco na história regional e, com seu número de visitantes vindos de todo Estado e a repercussão na imprensa, é de se supor que sua realização tivesse desdobramentos sobre eventos posteriormente realizados.

Outra questão a destacar é a de que, quando da criação do Serviço Estadual de Turismo (SETUR), em 1950, a promoção de eventos e festas terá destaque. O Plano de Turismo, então elaborado, tinha entre seus objetivos "organizar, anualmente, o Calendário Turístico do Rio Grande do Sul, aproveitando as principais manifestações de ordem cultural, artística, folclórica, econômica e outras que ofereçam real partido turístico" (HOHLFELDT e VALLES, 2008, p.25). Para materializar os objetivos, a estrutura do SETUR contava com a Seção de Propaganda, dividida nos setores de Publicidade; Relações Públicas, Imprensa e Informação; Certames e Exposições; Fotografia e Cinematografia (idem, grifo nosso).

Nas realizações do SETUR, destacam-se as festividades que começaram a movimentar o Estado, como a $2^{\text {a }}$ Festa das Hortênsias, em Gramado, no ano de 1961, e o $1^{\circ}$ Festival da Serra, em Canela, em 1962. Ambos foram organizados pelos seus recém-fundados Conselhos Municipais de Turismo, criados sob incentivo do SETUR. Em 1963 surgiu a Festa do Pêssego, na cidade de Pelotas; a $1^{\text {a }}$ Festa do Milho, em Guaporé; a Festa das Rosas, em Sapiranga,

\footnotetext{
${ }^{7}$ O Regulamento Geral foi produzido e editado pelo Comissariado Geral, que coordenou o evento, sendo editado em 1935.
} 
assim como, em Novo Hamburgo, a FENAC - Festa Nacional do Calçado (HOHLFELDT e VALLES, 2008, p.27).

Foi a partir da década de 1970, no mesmo Estado, que houve em concomitância à criação do Sistema Estadual de Turismo, a formulação de políticas públicas de incentivo à realização do que estamos propondo denominar como festas temáticas, nos distintos municípios. Na época, a maioria deles sofria com a falta de estruturas instaladas para atender as demandas e fluxos de turismo que começavam a movimentar as economias locais. Para viabilizar o turismo no local, essas festas - que se organizavam a partir de um tema - foram praticadas em diversas comunidades e contavam com a montagem de instalações provisórias para comercialização de alimentos e prática de lazer durante os dias de sua realização, o que permitia que os festejos fossem desfrutados não só pelos munícipes, mas também pelos visitantes e turistas que timidamente começaram a se aventurar até elas, mesmo na falta de infraestrutura mais adequada. Muitas dessas festas beneficiaram-se do legado recebido das comunidades coloniais alemãs e italianas, principais fluxos de migrantes que se instalaram no sul do Brasil ao longo do século XIX, que cultivavam a festa como forma de celebrar, comemorar e divertir.

Além disso, um decreto estadual de 1973 instituiu o Biênio da Colonização e Imigração, para que, durante dois anos, fossem incentivados estudos e promovidas festividades, exposições e concursos, com o objetivo de apresentar as "etnias como formas representativas do multiculturalismo gaúcho" (HOHLFELDT e VALLES, 2008, p.30), com destaque para a alemã, a italiana, a espanhola, a uruguaia, a polonesa, a japonesa, a israelita, a portuguesa, a indígena, entre outras. Destacam-se a comemoração, em 1974, do Sesquicentenário da Imigração Alemã e, em 1975, do Centenário da Imigração Italiana ao Rio Grande do Sul como eventos maiores. Diferentes comissões foram responsáveis pela "promoção de distribuição de cartazes, folhetos e demais materiais de divulgação dos festejos, com responsabilidade quanto a sua entrega ou remessa" (HOHLFELDT e VALLES, 2008, 31).

Esse cenário levará a que, nas décadas finais do século XX e na inicial do século XXI, as festas temáticas estejam em situação de destaque nos calendários turísticos (Ver Tabela 1). 
TABELA 1: Festas Temáticas no Rio Grande do Sul em 2011

\begin{tabular}{l|l}
\hline FESTA & CIDADE \\
\hline Festa Nacional da Uva & Caxias do Sul \\
\hline Festa do Peixe & Tramandaí \\
\hline FESTIQUEIJ & Carlos Barbosa \\
\hline Festa Nacional do Champanha - FENACHAMP & Garibaldi \\
\hline Encontro das Tradições Italianas - ENTRAI & Farroupilha \\
\hline Festa da Colônia & Gramado \\
\hline FENAVINHO Brasil - Festa Nacional do Vinho & Bento Gonçalves \\
\hline Festa Nacional da Vindima & Flores da Cunha \\
\hline Festa de Abertura da Vindima e EXPOMONTE & Monte Belo do Sul \\
\hline FENAKIWI - Festa Nacional do Kiwi & Farroupilha \\
\hline CHOCOFEST - Páscoa em Gramado & Gramado \\
\hline Natal Luz & Gramado \\
\hline Festa do Pinhão & São Francisco de Paula \\
\hline Festa Nacional da Maçã & Veranópolis \\
\hline Festa de Produtos Coloniais - FEPROCOL & Nova Pádua \\
\hline Festa Nacional do Churrasco & Lagoa Vermelha \\
\hline Festa das Amoras, Morangos e Chantily - FENAMOR & Feliz \\
\hline SUINOFEST & Encantado \\
\hline Festa do Agricultor & Barão do Triunfo \\
\hline Fest In Vêneto & Cotiporã \\
\hline Festa do Porco a Paraguaia & Maximiliano de Almeida \\
\hline Festa Nacional do Doce - FENADOCE & Pelotas \\
\hline Festa das Compotas & Taquara \\
\hline Festa do Mar & Rio Grande \\
\hline Festa Nacional do Milho - FENAMILHO & Santo Ângelo \\
\hline Festa Estadual do Feijão & Sobradinho \\
\hline Festa da Nacional da Erva Mate - FEMATE & Arvorezinha \\
\hline Festa do Moranguinho & Bom Princípio \\
\hline & Fo \\
\hline
\end{tabular}

Fonte: As autoras, 2012, a partir do Calendário Turístico do RS, 2011.

No até aqui descrito, se procurou demonstrar, portanto, que em especial nas primeiras décadas do século XX, o modelo das feiras mundiais foi assimilado no Brasil e no Rio Grande do Sul onde, guardadas as proporções, eventos similares foram realizados. Nessa vertente de influência não se pode deixar de incluir a importante presença do carnaval, que também contribui para o cenário contemporâneo das festas, em especial devido à visibilidade midiática que recebem os desfiles das grandes Escolas de Samba do Rio de Janeiro, a partir da década de 1970. Sem aprofundar a discussão em torno do carnaval no âmbito dessa argumentação, 
constata-se que seu crescimento tem levado à profissionalização do setor (MIGUEZ, 2009), que extrapola o Rio de Janeiro.

O carnaval acumula know how e cria um padrão estético que se imporá em diferentes cidades brasileiras; a "afirmação de novas linguagens estabeleceu patamares inéditos para organização da festa urbana, estimulados pelo poder público [para] tornar mais atraentes os espaços a ela destinados" (GUIMARÃES, 2009, p.85). No âmbito do carnaval do Rio de Janeiro, "a forma do desfile ${ }^{8}$ completou-se na década de 1950. Data de então a definição do perfil atual e característico cuja base é a escolha anual de um 'tema', logo desenvolvido como 'enredo'. 9 A transformação do enredo nas linguagens plástica e visual das fantasias e alegorias, e rítmicomusical do samba-enredo, comanda a confecção do desfile" (CAVALCANTI 2002, p. 49).

Exemplo significativo dessa situação de influência é o Natal Luz, realizado em Gramado/RS. O Natal Luz, tendo como tema a tradição germânica de comemoração da data, que inclui a forte presença da figura de Papai Noel, com seu trenó e renas, e da árvore de Natal, todos associados a luzes e brilhos, ganhou forte apelo popular quando organizado como evento. Em 2002, o carnavalesco Joãosinho Trinta foi contratado pelos gestores locais para qualificar o evento. Ele introduz, entre outros, o desfile pelas ruas e sua organização a partir do trabalho coletivo nos barracões, onde os carros alegóricos são produzidos com clara orientação estética carnavalesca. A presença de Joãosinho Trina, em Gramado, mesmo que na oportunidade ele tenha trazido sua equipe, foi complementada com a contratação de alguns carnavalescos de Porto Alegre ${ }^{10}$. A aproximação das lógicas e da estética do carnaval, portanto, se dará não apenas pela midiatização da festa, mas pela extrapolação do know how acumulado pelos

\footnotetext{
${ }^{8}$ Segundo Cavalcanti (2002, p.12), na experiência do Carnaval do Rio de Janeiro, ao longo do século "o desfile propiciou à cidade um canal de expressão e mediação de processos sociológicos importantes tais como a expansão da cidade rumo aos subúrbios e à periferia, a expansão das camadas médias e populares e sua interação $[\ldots] "$.

9 "O desenvolvimento do desfile expressa como que uma revolta contra a linearidade espacial e narrativa por ele assumida. Pois vejamos bem: em sua vivência concreta, o tempo de sua duração é, de certo modo, multiplicado, ou melhor, estilhaçado em mil cacos, pela maneira nada linear de apresentar um "enredo". 0 termo "enredo", extraído de formas eruditas de criação artística e utilizado na expressão corrente de "enredos carnavalescos", é profundamente enganoso. [...] Um desfile corresponde ao esquartejamento visual dos enredos, subdivididos em múltiplos tópicos, que se abrem, por sua vez, em muitos outros numa cadeia infindável, ou melhor, que só se fecha por necessidade externa: o tempo de sua apresentação se esgota" (CAVALCANTI, 2002, p.61).

${ }^{10}$ Conforme Zé Cartola, em entrevista aos autor em 23-09-2011
} 
carnavalescos cariocas e de outros grandes centros brasileiros, para outras manifestações festivas - urbanas, como o carnaval - em diferentes locais do Rio Grande do Sul e não mais restritos ao mês de fevereiro, para as 'carnavalizar'.

Um dos casos é o de Jose Carlos de Oliveira, mais conhecido como Zé Cartola, um carnavalesco com mais de trinta anos de atuação em Porto Alegre, principalmente como Mestre-Sala. Com formação acadêmica em Dança, após experiência com Joãosinho Trinta no Natal Luz, em Gramado:

Zé Cartola segue uma sequência de trabalhos voltados á área cultural, no interior do estado, com o desenvolvimento de desfiles temáticos. Sua trajetória iniciou com a $13^{\mathrm{a}}$ Festa do Moranguinho em 2009 na Cidade de Bom Princípio, realizou o desfile temático O Natal do Coração em São Sebastião do Caí em 2009 onde iniciou com seu colega de trabalho Sergio Guerra, foi coordenador do evento de escolha da Rainha da Bergamota em São Sebastião do Caí dando sequência a esse trabalho também realizou o desfile temático da Festa da Bergamota em 2010, também desenvolveu o desfile temático de natal em 2010 na cidade de Bom Princípio. ${ }^{11}$

Zé Cartola denomina como 'carnavalizar', às intervenções que realiza nas diferentes festas em que participa. Perguntado sobre o que seria 'carnavalizar' uma festa local, explica que seria incorporar a ela "todo o processo que se usa no carnaval: o cronograma, as alas [...] e também contar as histórias [...]". ${ }^{12}$ Refere-se, portanto, à estética narrativa peculiar ao carnaval, construída a partir de um enredo e à consonância tema-música-alegoria, estas trazendo os elementos volume, verticalidade, cores/brilho como centrais na linguagem carnavalesca.

Mesmo com origens muito mais antigas, a estrutura do carnaval, a partir dos desfiles das Escolas de Samba, é moderna. Portanto, como se procurou apresentar a partir dele e das feiras mundiais, suas marcas sobre as festas locais são bastante evidentes. Esse percurso, direta ou indiretamente, tem marcado as festas realizadas no sul Brasil, indicando que denominá-las como populares, não dá conta da sua complexidade. Por outro lado, se as mesmas forem olhadas como 'tradicionais' e, ato contínuo, acusadas de inautenticidade, indica-se, mais uma

\footnotetext{
${ }^{11}$ Disponível em http://zecartola2.blogspot.com, acessado em 26-01-12.

${ }^{12}$ Ze Cartola, em entrevista aos autores em 23-09-2011.
} 
vez, a pouca atenção dada às suas especificidades. Tais especificidades serão tratadas a seguir, para se propor a expressão festa temática, para conceituá-las.

\section{Festa Temática}

Considerando os pressupostos até aqui apresentados, propõem-se aplicar a expressão festa temática para caracterizar eventos que sejam fruto da Modernidade, mesmo que a sua inspiração primeira, em muitos casos, seja associada ao resultado de produção rural e, nesses termos, em íntima relação com a tradição cultural local, o que leva a que muitas vezes sejam ditas 'populares'. A Modernidade, a partir da presença da máquina, e mais especificamente da fábrica, no século XIX, altera modos de vida e introduz uma sensibilidade, inclusive em termos de desfrute do lazer e tempo livre, cada vez mais associados ao entretenimento (GASTAL, 2006).

As lógicas do entretenimento como o acontecimento com intensidade e espetacularização, como já colocado, acompanham as exposições mundiais, desde a primeira, realizada em Londres, em 1851, marcas que são transpostas ao Brasil - e ao Rio Grande do Sul, em particular - através de sucessivos eventos que nelas se inspiram. O que se tem destacado é que as práticas das exposições-feira induzem um novo pensar sobre a festa, no qual se associa à ideia de gozo e alegria, o desfrute de um evento planejado e, mesmo que não se coloque propriamente como um produto de mercado, com lógicas associadas a outras questões que não apenas o extravasamento social e individual, e a expressão da cultura local. Ou melhor, estaríamos em presença da consolidação de novos hábitos e comportamentos, nos quais a expressão cultural não mais se coloca na lógica das decorrências da forte presença do território, como nas culturas tradicionais, mas frente a novas identificações, associadas à Modernidade, agora permeadas pela máquina e pela produção em massa de objetos e ao entretenimento como atividade programada e geralmente paga, parte do sistema de produção que se estabeleceu.

Trigo (2003, p.26) afirma que "o conceito de entretenimento surgiu de forma mais específica ao longo do século XIX e XX, fruto da estruturação do capitalismo em sua fase pósindustrial”. Embora o teórico se refira mais especificamente aos produtos da indústria cultural 
- best-sellers, cinema, televisão, disco e, portanto, ainda da fase industrial - a palavra teria origem latina em inter (entre) e tenere (ter) que, via a inglesa entertainment, levaria ao

[...] 'que diverte como distração ou recreação' e a 'um espetáculo público ou mostra destinada a interessar e divertir'. Os conceitos referem-se sempre às origens latina da palavra e incorporam a ideia de 'ter entre'. O entretenimento nos leva cada vez mais para dentro dele e de nós mesmos' [...] (TRIGO, 2003, p.32 em parte citando Gabler).

Os produtos criados a partir da lógica do entretenimento colocam-se como 'acontecimento', já que marcados pela intensidade e pela espetacularização. À luz da Modernidade, o 'acontecimento' apresenta um sentido próximo ao que Boullón (1990) apresenta como 'momento': algo que não tem compromisso nem com o que vem antes, o passado, nem com o que se seguirá, o futuro, desencorajando qualquer possibilidade de pensamento crítico. $\mathrm{O}$ ‘acontecimento' deverá marcar-se pela intensidade e não pela extensividade.

Diria que algo é acontecimento enquanto diferença na sua própria ordem. E o que caracteriza a diferença é que o acontecimento não é um fato no tempo, ou seja, não é um fato novo enquanto distinto de qualquer outro ocorrido antes no tempo. O que o caracteriza como diferença é que o acontecimento temporaliza, ou seja, ele não está num presente de um antes e de um depois no tempo. Ele instala uma temporalidade: essa é sua diferença. De um lado ele abre em si uma latência de futuro, sem a qual ele não é um acontecimento de linguagem, sem a qual ele não significa, pois sem ela nada há aí de projeção. O acontecimento tem como seu um depois incontornável e próprio do dizer. Por outro lado, esse futuro próprio do presente do acontecimento funciona por um memorável que o faz significar (GUIMARÃES, 2001, p. 95).

Portanto, a temporalidade do acontecimento

[...] constitui um depois que abre lugar dos sentidos, e um passado que não é lembrança ou recordação de fatos anteriores. O passado é, no acontecimento, uma rememoração, ou seja, se dá como parte de uma nova temporalização, tal como a latência de futuro. É nessa medida que o acontecimento é diferença na sua própria ordem: o acontecimento é sempre uma nova temporalização, um novo espaço de convivialidade de tempos, sem a qual não há sentido, não há acontecimento de linguagem, não há enunciação (Idem ibidem). 
Essa temporalidade, associada à festa, permite que Ferreira (2009) fale em espaço-tempo da festa. E para que esse passado rememoração se dê de forma mais efetiva na festa, a espetacularização contribui para um processo que encaminha o onírico. Debord (1997), por sua vez, afirma que viveríamos sob a égide da sociedade do espetáculo. Para ele o espetáculo é 're-presentação', isto é, a vivência indireta, num contexto em que a realidade torna-se um pseudomundo à parte, um "momento que é falso" (DEBORD, 1997, p.16), por não mais implicar uma relação sensorial (pessoa-mundo) direta. Ou seja, é a representação que se torna imediata aos sentidos, na forma do espetáculo que, além de materializar o "discurso laudatório da sociedade sobre si" (Idem, p.20), significará o "equivalente geral abstrato de todas as mercadorias" (Idem, p.34). A sociedade do espetáculo implica a hegemonia do olhar - e, portanto, do estético - em detrimento dos demais sentidos.

Em termos de festas postas como acontecimento, significa dizer que luz, brilho e cores passaram a ser a ela associados. Retomando o carnaval como paradigmático dessa nova postura, mesmo que a Festa de Momo já incluísse a decoração de ruas do Rio de Janeiro desde o período colonial (GUIMARÃES, 2009, p. 73-74), no início do século XX ele se transformará num "bailado alucinante de cores", conforme publicado no Diário de Notícias de 3 de janeiro de 1932 (apud GUIMARÃES, 2009, p.76). Dentro dessa lógica da espetacularização, Ferreira (2009, p.25) fala no 'lugar carnavalesco' como "a instauração de um espaço-tempo urbano próprio à realização da festa carnavalesca".

Tais marcas são encontradas nas festas analisadas no Rio Grande do Sul, mesmo que sua espetacularização seja proporcional ao suporte financeiro de cada comunidade local. Significa dizer que haverá festas mais pobres ou eventos mais modestos no uso de luzes e sofisticação de materiais. No caso do Natal Luz, de Gramado/RS, por exemplo, mesmo quando seus organizadores utilizam sucata de plástico como matéria prima para decorar os espaços públicos, esse deve re-presentar o brilho e a sofisticação de materiais mais nobres.

Analisadas oito festas realizadas no Estado, é possível sistematizar algumas características presentes em todas elas:

a) a presença de uma temática agindo como eixo organizador; 
b) o eixo temático constituindo-se a partir de um imaginário, preferencialmente associado ao território, destacando-se nesses termos a produção agrícola presente no local, quer como economicamente hegemônica quer como diferencial - Uva, Pinhão; Kiwi; Maça; Morango; Pêssego... -, ou a outros referenciais simbólicos presentes na paisagem, como as hortênsias ou as rosas;

c) o eixo temático constituindo-se em imaginários associados a manifestações da cultura local e à identidade, como decorrentes do território: o artesanato (FEARTE), a gastronomia local (Festa do Doce, Poletaço, FESTIQUEIJO, Festa do Chucrute, entre outras), os costumes locais tradicionais (Festa da Colônia, Natal Luz);

d) forte presença de oferta gastronômica;

e) presença de feiras de pequeno, médio e grande porte para exposição e/ou venda de produtos locais; na atualidade, em muitos casos, predominantemente artigos populares de baixo custo;

f) programação cultural marcada pela participação de grupos locais, amadores, como corais de escolas, esquetes por grupos de clubes de mães, teatralizações por grupo de idosos, entre outros, para preencher horários e espaços ociosos, e grandes shows com músicos de repercussão nacional e popular, no horário noturno;

g) iniciativa ou forte apoio do setor público;

h) organização tendo como responsáveis grupos da comunidade, na forma de comissões comunitárias, menos por razões socioculturais que busquem a representação local no evento e mais por razões econômicas, para baixar custos de gestão, o que leva a certo amadorismo na realização;

i) a ritualização, não mais no seu sentido antropológico, mas com viés midiático, marcados pela espetacularização, como desfiles de corsos ou carros alegóricos, eleições de princesas e rainhas;

j) íntima associação com o turismo, quer a priori, desde a sua concepção, quer a posteriori, por atrair fluxos de visitantes; 
A expressão festa temática, como uma categorização de festa foi localizada na revisão bibliográfica realizada, em um único trabalho ${ }^{13}$. Tampouco está presente em documentos disponibilizados pelo Ministério do Turismo, nos quais são apresentadas as categorias Festas, Festas Populares, Festivais e Festas Juninas. A expressão festa temática tem sido utilizada na imprensa para designação de eventos de caráter social, associadas a marcas comerciais, a eventos para o público jovem, organizadas em termos de temática a ser seguida pelos participantes nas suas indumentárias - Festa Anos 80, Festa do Pirata, Festa do Ridículo - ou então, eventos com decoração específica, mais comumente utilizadas em festas infantis como tema central, com personagens da mídia globalizada, como Cinderela, Shrek, Pinóquio, Moranguinho, etc.

Analisando os termos da expressão proposta, ter-se-ia festa como a cerimônia com que se celebra um fato (NEGRINE E BRADACZ, 2006), e, sendo uma celebração, caracterizada por sua função de "exaltar, tornar célebre, proclamar, promover, em suma, dar a conhecer, por meio de ostentação festiva" o objeto da celebração (RIBEIRO, 1998, p.67). A palavra temática seria a soma do radical sema $\geq$ do grego théma e do latim thêma, à desinência ou sufixo. O radical diz-se da "proposição que vai ser tratada ou demonstrada", "assunto" (CUNHA, 2007, p. 761). Gonzales Viaña (2006) recorre ao Dicionário de Língua Espanhola da Real Academia Española, que aponta 'tematizar' como “converter em tema central de um discurso, texto, discussão, obra de arte, etc.”. O substantivo temática/o seria "o conjunto de temas parciais contidos em um assunto geral". A aplicação de temático/a como adjetivo diz respeito ao "que se arruma, dispõe ou executa segundo o tema ou assunto de qualquer matéria" (GONZALEZ VIAÑA, 2006, p. 87 - tradução das autoras).

Assim, se propõe utilizar a expressão festa temática para designar as festas que se dão como acontecimento e entretenimento, tendo o seu imaginário organizado preferencialmente a partir de produto ou expressão cultural tradicional local, sendo esse o tema de festa. À festa temática associa-se uma condição de oferta de entretenimento e, em decorrência, coloca-se como atrativo para a comunidade local e para visitantes externos a ela, marcando-se pelo apoio e mesmo patrocínio do poder público, sendo a sua organização entregue, senão de fato, pelo

\footnotetext{
13 A expressão festa temática foi encontrado apenas no artigo titulado "Presença da Ruralidade em Municípios Gaúchos: o exemplo de Silveira Martins, RS”, de autoria de ALVES, LINDNER e FERREIRA (2009).
} 
menos simbolicamente, a representantes da comunidade, muitas vezes atuando de forma voluntária, numa estrutura gerencial a partir de comissões de trabalho.

Reportando a conceituação proposta por Ashton (2000) para parques temáticos, algumas condições apontadas podem ser transpostas para a festa temática: (1) ter um custo de entrada e não por atração; (2) ser construída a partir das necessidades dos visitantes; (3) proporcionar sensações físicas; (4) ser um destino a atrair visitação por si mesma. Portanto, pressupõe-se que as festas temáticas se coloquem como um espaço de diversão e entretenimento, que ofereça aos visitantes sistemas que lhes sejam essenciais, como espaço para ver, comer, comprar e vivenciar, cobrando-se ou não pelos serviços um valor de ingresso, devendo a festa constituir-se em uma atração em si mesma.

A mesma análise dos parques temáticos, como proposta por Ashton (2000), permite encaminhar ao viés da festa, que (1) os visitantes externos são atraídos pela busca de novas experiências; (2) que a festa é uma forma de atrair visitante para os destinos menos favorecidos em termos de infraestrutura; (3) que a realização de tais eventos não é menosprezada por destinos turísticos consagrados, que também as realizam sob pressões de mercado, na busca de vantagens competitivas sobre outras localidades; (4) que o papel do setor público no seu desenvolvimento é fundamental, muitas vezes com vistas ao turismo; e (5) que ela se coloca como busca de diferenciação do produto em relação a outras ofertas do mercado, a palavra festa sendo utilizada para induzir à ideia de alegria e confraternização.

\section{Concluindo}

A sociedade pós-industrial tem no tempo livre um importante produto de mercado. Dessa contingência não escapam as festas, mesmo que na sua origem elas estejam associadas a expressões culturais das comunidades locais, em especial as rurais. A urbanização é, hoje, um fenômeno global, inclusive na sua incorporação das ruralidades no espaço das cidades.

A análise realizada no corpo do presente artigo centra-se nos primórdios desse cenário, colocando possíveis influências que teriam condicionado a dinâmica das festas, de eventos populares, ou seja, com íntima ligação com as culturas locais, para eventos subordinados às demandas da Modernidade e, nessa condição, a demandas de mercado. Destacaram-se duas 
vertentes nesses estudos preliminares. A primeira estaria relacionada com as exposições mundiais europeias, surgidas na segunda metade do século XIX e expandidas no seu modelo inclusive para regiões economicamente periféricas, nas primeiras décadas do século $\mathrm{XX}$. $\mathrm{O}$ Brasil estará inserido nesse contexto. Com a realização progressiva de exposições-feiras cada vez maiores, mesmo em estados mais meridionais, como o Rio Grande do Sul, as mesmas acabam por se mesclar com festas locais, criando um híbrido a que estamos propondo chamar de festa temática.

A segunda vertente seria o carnaval que, como festa urbana por excelência, institucionaliza-se na segunda metade do século XX, com vasta repercussão nas mídias: do rádio às revistas semanais, passando pelo cinema e chegando as coberturas privilegiadas dadas pelos canais de televisão, à festa. O carnaval profissionaliza-se e acumula técnicas e tecnologias para a festa. Tão ou mais importante, cria uma visualidade com muita cor e brilho e com proporções nos seus carros alegóricos e desfiles com milhares de participantes, que dialogam com a dimensão urbana dos prédios e avenidas.

As festas locais não ficaram imunes a essas influências, que aos poucos incorporam. Criam-se híbridos, que antes do que descaracterizar as festas comunitárias, buscam adequá-las aos novos imaginários de entretenimento, que as colocam como acontecimento. Do acontecimento espera-se intensidade e espetacularização.

Dessa maneira, as festas mudam, porque a sociedade que as produz, também muda, sendo frágil imputar ao turismo e ao turista, responsabilidades maiores num processo mais profundo e com causas interligadas. Nos atuais processos, o pipoqueiro foi substituído pela máquina de pipocas, o fotógrafo lambe-lambe pelos dispositivos de captação de imagens dos celulares.

Ao propor denominar as festas contemporâneas, antes dita populares, como festas temáticas, busca-se abarcar as novas contingências de sua realização e provocar uma discussão que, talvez, permita a reflexão que leve à preservação das antigas formas de festejar como, de fato, populares, no seu sentido mais amplo. 


\section{Referências}

ALCADE, A.C. E OLMOS, F.C. \& GONZALEZ, A.G. Reproducion de identidades em la romeria del Valle de Zalabi em Santalo. BRUXO, A.C., BECERRA, M.G. (orgs). La religiosidade popular, v. III. Barcelona: Editorial Anthropos, 1989.

AMARAL, L. Festas, festivais, festividades: algumas notas para a discussão de métodos e técnicas de pesquisa sobre festejar no Brasil. Anais do II Colóquio Festas e Sociabilidades (CIRS/CASO/CEFET). Universidade Federal do Rio Grande do Norte, 2008.

ASHTON, M.S.G. Parque Temático Mini Mundo: comunicação e turismo na pós-modernidade. Dissertação do Mestrado em Comunicação Social - PUCRS: Porto Alegre, 2000.

BAKHTIN, M. A Cultura Popular na Idade Média e no Renascimento - O contexto de François Rebelais. São Paulo: Editora Hucitec/Annablume, 2002.

BOULLÒN, R.C. Las actividades turísticas y recreacionales - El hombre como protagonista. México: Trillas, 1990.

CAVALCANTI, M.L.V.C. As grandes festas. In: SOUZA, M. de e WEFFORT, F. (orgs.). Um Olhar sobre a cultura brasileira. Rio de Janeiro: Funarte/Ministério da Cultura, p. 293-31, 1998.

CAVALCANTI, M.L.V.C. Os sentidos no espetáculo. Revista de Antropologia, V. 45 n.1. São Paulo: USP, 2002. Disponível em http://www.scielo.br/scielo.php?script=sci_arttext\&pid=S003477012002000100002.

CUNHA, A.G. Dicionário etimológico da língua portuguesa. Rio de Janeiro: Lexicon Editora Digital, 2007.

DAMASCENO, A. Artes plásticas no Rio Grande do Sul (1755-1900). Porto Alegre: Globo, 1971.

DEBORD, G. A sociedade do espetáculo: comentários sobre a sociedade do espetáculo. Rio de Janeiro: Contraponto, c1997.

FERREIRA, F. Um carnaval à francesa: a construção da folia na cidade de Nice. In. CAVALCANTI, M.L. e GONÇALVES, R. (orgs.). Carnaval em múltiplos planos. Rio de Janeiro: Aeroplano, FAPERJ, 2009.

GASTAL, S. Alegorias urbanas: o passado como subterfúgio: Tempo, espaço e visualidade na pósmodernidade. São Paulo: Papirus, 2006.

GONZALEZ VIANA, M.C. Turismo y ciudad: nuevas tendencias. Buenos Aires: Turísticas, 2006.

GUIMARÃES, E. Um mapa e suas ruas. In ORLANDI, E.P (org). Cidade atravessada: os sentidos públicos no espaço urbano. Campinas: Pontes, 2001.

GUIMARÃES, H.M. Uma cidade engalanada! As decorações de ruas e salões de baile no carnaval carioca. In. CAVALCANTI, M.L. e GONÇALVES, R. (orgs.). Carnaval em múltiplos planos. Rio de Janeiro: Aeroplano, FAPERJ, 2009.

HOHLFELDT, A.; VALLES, R.R. Dois pioneiros da comunicação no Rio Grande do Sul: Oswaldo Goidanich, Roberto Eduardo Xavier [recurso eletrônico]. Porto Alegre: Edipucrs, 2008. Disponível em www.pucrs.br/edipucrs/doispioneiros.pdf

MACEDO, C.C. Tempo de gênesis. São Paulo: Brasiliense, 1986.

MACHADO, N.H.N. A exposição do Centenário Farroupilha: Ideologia e arquitetura. Dissertação de Mestrado. PUCRS. Porto Alegre, 1990. 
MIGUEZ, P. Algumas notas sobre a economia do Carnaval da Bahia. In CALABRE, F. Políticas culturais: reflexões e ações. São Paulo: Itaú Cultural; Rio de Janeiro: Fundação Casa de Rui Barbosa, 2009. Disponível em http://www.itaucultural.org.br/bcodemidias/001513.pdf

NEGRINE, A.; BRADACZ, L. Cultura, lazer e turismo: A Festa da Colônia de Gramado/RS. Porto Alegre: Edição dos Autores, 2006.

NERY, A.R. Etnografando na cidade: Práticas, narrativas e construções simbólicas sobre o Turismo no Centro Luiz Gonzaga de Tradições Nordestinas/RJ. Pasos, v. 9(3) Special Issue, p. 31-44, 2011. Disponível em www.pasosonline.org/Publicados/9311special/PS0311_04.pdf

PESAVENTO, S.J. Exposições universais: Espetáculo da Modernidade do século XIX. São Paulo: Hucitec, 1997.

POSSAMAI, Z. Fotografia, História e Vistas Urbanas. Disponível em http://www.scielo.br/pdf/his/v27n2/a12v27n2.pdf 2007. Acessado em 07-12-2011.

RIBEIRO, C.M. P. A Celebração da Festa: conhecer e de dar a conhecer a própria identidade. Tese de Doutorado em Educação da Universidade Federal de São Carlos: SP, 1998.

RIBEIRO, C.M. P. Festa \& identidade: Como se fez a Festa da Uva. Caxias do Sul, RS: EDUCS, 2002.

RIBEIRO, M. Festas populares e turismo cultural: Inserir e valorizar ou esquecer? O caso dos Moçambiques de Osório, Rio Grande do Sul. Pasos, v.2, n.1, p. 47-56, 2004. Disponível em http://redalyc.uaemex.mx/redalyc/pdf/881/Resumenes/88120104_Resumo_5.pdf

TRIGO, L.G.G. Entretenimento: Uma critica aberta. São Paulo: Senac, 2003.

VILLADARY, A. Fête et vie quotidienne. Paris: Les Éditions Ouvrières, 1968.

ZOTTIS, A.M. A Contribuição dos Cartazes da Festa da Uva na Construção da Imagem Turística de Caxias do Sul. Dissertação (Mestrado) - Universidade de Caxias do Sul, Programa de Pós-Graduação em Turismo, 2003. $\quad$ Disponível em www.ucs.br/ucs/posgraduacao/strictosensu/turismo/dissertacoes/.../04

\section{Recebido em: 03/05/2012}

Aprovado em: 17/08/2012 